\title{
Negatively charged low-density lipoprotein is associated with atherogenic risk in
}

\section{hypertensive patients}

Jungo Urata, $\mathrm{MD}^{1)}$, Satoshi Ikeda, $\mathrm{MD}, \mathrm{PhD}^{1)}$, Seiji Koga, $\mathrm{MD}, \mathrm{PhD}^{1)}$, Tomoo Nakata, $\mathrm{MD}^{1)}$, Tomohiko Yasunaga, $\mathrm{MD}^{1)}$, Koichiro Sonoda, $\mathrm{MD}, \mathrm{PhD}^{1)}$, Yuji Koide, $\mathrm{MD}^{1)}$, Naoto Ashizawa, $\mathrm{MD}, \mathrm{PhD}^{1)}$, Shigeru Kohno, $\mathrm{MD}, \mathrm{PhD}^{2)}$, and Koji Maemura, $\mathrm{MD}, \mathrm{PhD}^{1)}$.

1) Department of Cardiovascular Medicine, Nagasaki University Graduate School of Biomedical Sciences, and ${ }^{2)}$ Second Department of Internal Medicine, Nagasaki University School of Medicine, 1-7-1 Sakamoto, Nagasaki 852-8501, Japan

Corresponding author: Satoshi Ikeda, MD, $\mathrm{PhD}$

Department of Cardiovascular Medicine, Nagasaki University Graduate School of Biomedical Sciences, 1-7-1 Sakamoto, Nagasaki 852-8501, Japan

Tel: +81-95-819-7288; Fax: +81-95-819-7290

E-mail: sikeda@nagasaki-u.ac.jp 


\section{Abstract}

Negatively charged low-density lipoprotein (LDL), generated via multiple processes such as oxidation, acetylation, or glycosylation, plays a key role in the initiation and progression of atherosclerosis and related diseases. Anion-exchange high performance liquid chromatography (AE-HPLC) can subfractionate LDL into LDL-1, LDL-2 and LDL-3 based on LDL particle charge, but the clinical significance of LDL subfractions has not yet been elucidated. The aim of this study was to determine the clinical significance of these fractions with particular regard to atherogenic risk in hypertensive patients.

Ninety-eight patients with essential hypertension (age, $67.0 \pm 10.7$ years; 54 males) were enrolled in the present study. The relationships between LDL subfractions and atherogenic risk factors, including lipid profiles, blood pressure and plasma 8-isoprostane as a marker of oxidative stress, were examined.

LDL-1 levels significantly and negatively correlated with body mass index $(r=-0.384$, $\mathrm{p}<0.001)$, systolic blood pressure $(\mathrm{r}=-0.457, \mathrm{p}<0.001)$, non-high-density lipoprotein cholesterol levels $(\mathrm{r}=-0.457, \mathrm{p}<0.001)$ and 8 -isoprostane levels $(\mathrm{r}=-0.415, \mathrm{p}<0.001)$. LDL-3, which is the most negatively charged fraction of total LDL, significantly and positively correlated with these parameters $(\mathrm{r}=0.267,0.481,0.357$, and 0.337 , 
respectively). LDL-1 levels were significantly lower ( $\mathrm{p}<0.001)$, and LDL-2 and LDL-3 levels were significantly higher (each $\mathrm{p}<0.001$ ) in patients with poorly controlled hypertension than in patients with well-controlled hypertension. In addition, an increase in the total number of traditional risk factors at time of study participation, but not previous diagnosis, was associated with a decrease in LDL-1 levels and increases in LDL-2 and LDL-3 levels. These data suggest that LDL subfractions are associated with multiple atherogenic risk factors and that treatment to modify these risk factors could result in changes in LDL subfraction levels. In conclusion, LDL subfractions isolated by AE-HPLC may represent a marker of atherogenic risk in patients with hypertension.

Key words: negatively charged LDL, LDL-subfractions, oxidative modification, hypertension, atherogenic risk 


\section{Introduction}

Growing evidence from both in vivo and in vitro studies shows that the qualitative rather than quantitate proprieties of low-density lipoprotein (LDL) plays a key role in the initiation and progression of atherosclerosis.(1-5) LDL particles are heterogeneous in density, size and chemical composition, and LDL size correlates positively with high-density lipoprotein (HDL) levels and negatively with triglycerides levels. Small dense LDL is an atherogenic lipoprotein and has been designated as an emergent cardiovascular risk factor by the National Education Program Adult Treatment Panel III (NCEP ATP III).(3) The atherogenicity of small dense LDL is related to its susceptibility to oxidative modification. $(3,6,7)$ Oxidative modification can change the charge property of particles (8), and negatively charged LDL exerts various proatherogenic effects and properties, including cytotoxity, increased leukocyte recruitment, and impaired angiogenesis and LDL receptor binding.(9)

Negatively charged LDL, which is generated through a peroxidative process, contains more lipoperoxides and cholesterol oxides and less $\alpha$-tocopherol than native LDL.(10-14) In contrast, Sánchez-Quesada et al.(15) reported that the proportion of malondialdehyde, fatty acid hydroxides and antioxidants in negatively charged LDL is similar to that in 
positively charged LDL. Thus, there are some discrepancies among reports of the physiochemical characteristics of negatively charged LDL. Based on previous reports, the concentrations of malondialdehyde-modified LDL (MDA-LDL) or oxidized LDL (oxLDL), (i.e., oxidized forms of LDL) in total LDL are considerably lower than that of negatively charged LDL ( 0.1 to $0.5 \%$ vs. 1 to $10 \%$, respectively),(10-17) suggesting that most negatively charged LDL has not been generated by oxidative modification. Indeed, a variety of processes and factors, including oxidation, acetylation, nonenzymatic glycosylation, enrichment of non-esterified fatty acid, platelet activating factor acetylhydrolase, and enzymatic modification by phospholipase A2, can modify native LDL to negatively charged LDL.(18) In human studies, an increase of negatively charged LDL is associated with a high incidence of cardiovascular events in patients with hypercholesterolemia,(19-21) hypertriglyceridemia,(22) diabetes(23-26) or renal failure.(27) Thus, negatively charged LDL may be generated through multiple processes related to atherogenesis.

It is currently possible to isolate negatively charged LDL from plasma. Two techniques are used to separate LDL by electrical charge: ion-exchange chromatography(22, 28) and capillary isotachophoresis (cITP). $(29,30)$ An assay of LDL subfractions using 
anion-exchange high performance liquid chromatography (AE-HPLC), in which LDL is subfractionated into LDL-1, LDL-2 and LDL-3 in order of increasing particle electronegativity, has been developed, $(31,32)$ whereas previous evaluations by ion-exchange chromatography could only isolate two subfractions (i.e., negatively or positively charged LDL). This technique was based on the finding that extensive fragmentations of apolipoprotein B by oxidation are associated with increased negative charge in LDL particles.(32) Furthermore, Bittolo-Bon and Cazzolato used ion-exchange HPLC as a standard technique measuring negatively charged LDL and reported the presence of the faster subfraction in cITP strongly correlated to plasma concentration of negatively charged LDL by ion-exchange HPLC.(33) Thus, we used AE-HPLC to measure electronegativity of LDL in this study.

The significance of negatively charged LDL in humans has been elucidated in patients with a known high-risk of atherogenesis but not in patients with hypertension. Thus, the goal of this study was to characterize the utility of negatively charged LDL isolated by AE-HPLC as an atherogenic marker in patients with essential hypertension. 


\section{Materials and Methods}

This study enrolled 98 patients with essential hypertension (defined as undergoing treatment with antihypertensive agents, or as systolic blood pressure of $\geq 140 \mathrm{mmHg}$ and/or diastolic blood pressure of $\geq 90 \mathrm{mmHg}$ on two recent measurements). Blood pressure was measured using a mercury sphygmomanometer in the seated position after $5 \mathrm{~min}$ at rest.

Poorly controlled hypertension was defined as systolic blood pressure $\geq 140 \mathrm{mmHg}$ and/or diastolic blood pressure $\geq 90 \mathrm{mmHg}$, while well-controlled hypertension was defined as systolic blood pressure $<140 \mathrm{mmHg}$ and diastolic blood pressure of $<90 \mathrm{mmHg}$ in response to antihypertensive agents. Poorly controlled dyslipidemia was defined as LDL-cholesterol (LDL-C) $\geq 140 \mathrm{mg} / \mathrm{dl}$, triglycerides $\geq 150 \mathrm{mg} / \mathrm{dl}$ or high-density lipoprotein cholesterol (HDL-C) $<40 \mathrm{mg} / \mathrm{dl}$ with or without lipid-lowering agents. Poorly controlled diabetes was defined as fasting blood glucose $\geq 126 \mathrm{mg} / \mathrm{dl}$ or hemoglobin A1c (HbA1c) $\geq 6.5 \%$ with or without anti-diabetes medications. Patients with severe liver, renal or respiratory diseases, active infectious and inflammatory diseases, acute heart failure, unstable angina or secondary hypertension were excluded from the study. The Ethics Committee of Nagasaki University School of Medicine approved the study, which also conformed to the Declaration of Helsinki. All patients provided written, informed consent 
to participate in all procedures associated with the study.

Body mass index (BMI) was calculated as weight $/ \mathrm{height}^{2}\left(\mathrm{~kg} / \mathrm{m}^{2}\right)$. Blood samples were obtained from the antecubital vein in the morning after an overnight fast. Hematological and biochemical parameters, including lipid profiles, fasting blood glucose and HbA1c, were analyzed.

Subfractions of LDL in plasma were measured by AE-HPLC using an industry-standard analytical platform (SRL, Inc., Tokyo, Japan) as previously described.(31) This method chromatographically subfractionates LDL in a stepwise manner on a ProtEx-DES anion-exchange column in order of increasing electronegativity into LDL-1, LDL-2 and LDL-3 subfractions. The amount of each fraction is described as a ratio (\%) of the total LDL level. Total plasma levels of 8-isoprostane, used as a marker of oxidative stress, and highly sensitive C-reactive protein (hs-CRP), as a marker of inflammation, were also measured using an industry-standard analytical platform (SRL, Inc.).

We examined the relationship between LDL subfractions and atherogenic risk factors and whether treatment for atherogenic risk factors affected the levels of LDL subfractions.

Data were statistically analyzed using SPSS II version 11 software (SPSS Inc., Chicago, 
IL, USA). Relationships between variables were determined by Pearson's correlation analysis. Differences between two groups were analyzed using unpaired Student's t-test. LDL subfractions levels vs. number of atherogenic risk factors were compared using repeated measures ANOVA, followed by the Bonferroni post hoc test. Data are presented as means $\pm \mathrm{SD}$. P values of $<0.05$ were considered statistically significant. 


\section{Results}

Patient characteristics are summarized in Table 1. The average age was 67.0 years, and most patients received antihypertensive medications.

Systolic and diastolic blood pressure positively correlated with LDL-1 and negatively correlated with LDL-2 and -3 (Figure 1). BMI, LDL-C, and 8-isoprostane were significantly higher in patients with poorly controlled hypertension than in patients with well-controlled hypertension (Table 2). Further, LDL-1 levels were significantly lower $(\mathrm{p}<$ 0.001 ) and LDL-2 and LDL-3 levels were significantly higher (each $p<0.001$ ) in patients with poorly controlled hypertension than in patients with well-controlled hypertension (Figure 2). As summarized in Table 3, BMI, non-HDL-C, and 8-isoprostane positively correlated with LDL-1 levels and negatively correlated with LDL-2 and LDL-3 levels. Fasting blood glucose and HbA1c were weakly, but significantly, correlated with LDL-3 levels. In contrast, hs-CRP did not correlate with LDL subfraction levels.

Because multiple atherogenic risk factors were associated with LDL subfractions, the relationship between LDL subfractions levels and the number of traditional risk factors (e.g., hypertension, dyslipidemia and diabetes mellitus) was assessed. As the number of risk factors present at the time of study evaluation increased, LDL-1 decreased significantly and 
LDL-2 increased significantly. LDL-3 levels were significantly higher in patients with two or three risk factors than in those with no risk factors. In contrast, there were no significant differences in LDL subfraction levels based on the number of previously diagnosed risk factors (Figure 3). 


\section{Discussion}

The present study evaluated the significance of LDL subfractions, specifically, negatively charged LDL separated by AE-HPLC, in patients with essential hypertension and found an association between LDL subfractions and atherogenic risk factors, including blood pressure, non-HDL-C, BMI, and 8-isoprostane. Furthermore, as the number of atherogenic risk factors diagnosed at time of study (but not previous diagnoses) increased, LDL-1 levels decreased and LDL-2 and LDL-3 levels increased.

Negatively charged LDL is generated by various processes and leads to atherosclerosis.(18) Oxidation of LDL is one of these processes. Avagato and colleagues reported that negatively charged LDL was associated with decreased vitamin E content, increased thiobarbituric acid reactive substances and conjugated dienes, and poor affinity towards LDL receptors.(13, 14) Increasing oxidative susceptibility and decreasing concentrations of antioxidants is associated with decreasing LDL size. Smaller LDL is taken up more easily by arterial tissues and is associated with decreased receptor-mediated uptake and increased proteoglycan binding.(3) The negatively charged LDL content is higher in the dense LDL fraction than in the light LDL fraction.(34) Thus, small dense LDL, which is an atherogenic phenotype of lipoprotein, is associated with negatively 
charged LDL. Indeed, Noda, et al.(35) demonstrated that negatively charged LDL isolated by cITP was present within the small dense LDL fraction. A recent study has demonstrated that negatively charged LDL was internalized via the lectin-like oxidized LDL receptor (LOX-1), which is an oxidized LDL receptor in endothelial cells. This process resulted in impairments of Akt-mediated growth and survival signals.(36)

Experiments that use the AE-HPLC technique to separate LDL by particle electronegativity have shown that decreasing concentrations of LDL-1 and increasing concentrations of LDL-2 or LDL-3 reflect oxidative LDL modification.(31, 32, 37-40) Yamaguchi et al.(32) found that LDL-1 levels decreased and LDL-3 levels increased when LDL oxidative status was increased by incubating native LDL from rabbit plasma with 5 $\mu \mathrm{M} \mathrm{CuCl}{ }_{2}$ for various periods. Moreover, Watanabe heritable hyperlipidemic rabbits have higher levels of LDL-2, LDL-3 and thiobarbituric acid reactive substances (a marker of lipid peroxidation) than normolipidemic Japanese white rabbits, and concentrations of total hydroxyoctadecadienoic acid, $7 \alpha$ - and $7 \beta$-hydroxycholesterol and 8 -isoprostane, which are biomarkers of lipid peroxidation, are higher in LDL-3 than in LDL-1 and LDL-2 in human plasma.(31) In the present study, 8-isoprostane levels were negatively correlated with LDL-1 and positively correlated with LDL-2 and -3, and blood pressure values correlated 
with LDL subfractions in a similar manner. Elevated blood pressure induces an increased mechanical stretch force on vessel walls, which results in an increased production of reactive oxygen species via the NADPH oxidase system.(41, 42) Furthermore, angiotensin II also causes hypertension by producing reactive oxygen species via the NADPH oxidase system.(43) Thus, oxidative stress is considered to be a cause and/or a consequence of hypertension. Conversely, antioxidants, such as superoxide dismutase and tempol (4-hydroxy-2,2,6,6-tetramethyl piperidinoxyl), decrease blood pressure in spontaneously hypertensive rats but not in normal rats.(44) In a preliminary study, lowering blood pressure with olmesartan, an angiotensin II receptor blocker, increased levels of serum LDL-1, decreased levels of serum LDL-2 and LDL-3, and decreased plasma 8-isoprostane levels at 3 and 6 months (data not shown). In addition, negatively charged LDL subfractions were lower in patients with hypertension than in those with blood pressure that was well controlled by antihypertensive medications (Figure 2). This suggests that appropriate treatment of this risk factor resulted in lower levels of negatively charged LDL. Thus, elevated blood pressure-induced oxidative modification may be associated with reversible changes in negatively charged LDL levels.

This study also demonstrated that the total number of risk factors present upon 
examination in this study (but not previous diagnoses) correlated with LDL subfraction levels. Given the findings in Table 3, this suggests that negatively charged LDL is related to various atherogenic risk factors that are currently or recently present among the patient population.

There was no relationship between hs-CRP and LDL subfractions in this study. Indeed, inflammation is a known modifier of electronegativity. $(18,28)$ Because the average level of hs-CRP in our patients was higher than that reported in previous studies of patients with atherosclerosis, $(45,46)$ some of the patients in the present study population may have subclinical inflammation other than that related to atherosclerosis, and this may have obscured the relationship between hs-CRP and LDL subfraction levels.

\section{Limitations}

This study was conducted in a small cohort. Levels of 8 -isoprostane were used as a marker of oxidative stress for comparison with LDL subfractions. Other markers of oxidative stress, such as malondialdehyde-modified LDL, hydroxyoctadecadienoic acid and 8-hydroxydeoxyguanosine, may be required for further corroboration. Although smoking is highly associated with oxidative stress,(38) we found no relationships between smoking and LDL subfractions, possibly because we did not assess the extent of smoking in our 
patients (i.e., packs-per-day, duration, etc.). Levels of small dense LDL are higher in patients with hypertension than in those without hypertension.(47) However, the present study did not assess small dense LDL levels and therefore cannot describe the relationship between small dense LDL levels and negatively charged LDL. Given that small dense LDL is a component of non-HDL cholesterol, our finding of a significant correlation between LDL subfractions isolated by AE-HPLC and non-HDL cholesterol may reflect the association between small dense LDL and negatively charged LDL.

This study assessed the association between negatively charged LDL and atherogenic risk factors. However, a prospective study would be required to definitely establish the clinical utility of LDL subfractions in predicting cardiovascular events. Regardless, we demonstrated that LDL subfractions were associated with multiple atherogenic risk factors related to oxidative modification in patients with essential hypertension. Since these risk factors have already been validated as good predictors of cardiovascular events, the present data already support the significance of LDL subfractions in the clinical setting to some extent.

In conclusion, LDL subfractions isolated by AE-HPLC may represent a marker of atherogenic risk in patients with hypertension. 


\section{Acknowledgement}

This study was partly supported by JSPS Grant-in-Aid for Scientific Research (C) (21590902) (to S.I.). 


\section{References}

1. Steinberg D. (1997) Low density lipoprotein oxidation and its pathobiological significance. J Biol Chem 272: 20963-6

2. Berliner JA, Navab M, Fogelman AM, Frank JS, Demer LL, Edwards PA, Watson AD, Lusis AJ. (1995) Atherosclerosis: basic mechanisms. Oxidation, inflammation, and genetics. Circulation 91: 2488-96

3. Rizzo M, Berneis K. (2007) Who needs to care about small, dense low-density lipoproteins? Int J Clin Pract 61: 1949-56

4. Tavridou A, Efthimiadis A, Efthimiadis I, Manolopoulos VG. (2010) Simvastatin-induced changes in circulating oxidized low-density lipoprotein in different types of dyslipidemia. Heart Vessels 25: 288-93

5. Dong K, Ge JH, Gu SL, Li S, Zhu WG, Fan FY, Zhu JH. (2011) Ox-LDL can enhance the interaction of mice natural killer cells and dendritic cells via the CD48-2B4 pathway. Heart Vessels

6. Packard CJ. (2006) Small dense low-density lipoprotein and its role as an independent predictor of cardiovascular disease. Curr Opin Lipidol 17: 412-7

7. Berneis KK, Krauss RM. (2002) Metabolic origins and clinical significance of LDL 
heterogeneity. J Lipid Res 43: 1363-79

8. La Belle M, Blanche PJ, Krauss RM. (1997) Charge properties of low density lipoprotein subclasses. J Lipid Res 38: 690-700

9. Sanchez-Quesada JL, Benitez S, Ordonez-Llanos J. (2004) Electronegative low-density lipoprotein. Curr Opin Lipidol 15: 329-35

10. Sevanian A, Bittolo-Bon G, Cazzolato G, Hodis H, Hwang J, Zamburlini A, Maiorino M, Ursini F. (1997) LDL- is a lipid hydroperoxide-enriched circulating lipoprotein. J Lipid Res 38: 419-28

11. Sevanian A, Hwang J, Hodis H, Cazzolato G, Avogaro P, Bittolo-Bon G. (1996) Contribution of an in vivo oxidized LDL to LDL oxidation and its association with dense LDL subpopulations. Arterioscler Thromb Vasc Biol 16: 784-93

12. Hodis HN, Kramsch DM, Avogaro P, Bittolo-Bon G, Cazzolato G, Hwang J, Peterson H, Sevanian A. (1994) Biochemical and cytotoxic characteristics of an in vivo circulating oxidized low density lipoprotein (LDL-). J Lipid Res 35: 669-77

13. Cazzolato G, Avogaro P, Bittolo-Bon G. (1991) Characterization of a more electronegatively charged LDL subfraction by ion exchange HPLC. Free Radic Biol Med 11: 247-53 
14. Avogaro P, Bon GB, Cazzolato G. (1988) Presence of a modified low density lipoprotein in humans. Arteriosclerosis 8: 79-87

15. Sanchez-Quesada JL, Camacho M, Anton R, Benitez S, Vila L, Ordonez-Llanos J. (2003) Electronegative LDL of FH subjects: chemical characterization and induction of chemokine release from human endothelial cells. Atherosclerosis 166: $261-70$

16. Nishi K, Itabe H, Uno M, Kitazato KT, Horiguchi H, Shinno K, Nagahiro S. (2002) Oxidized LDL in carotid plaques and plasma associates with plaque instability. Arterioscler Thromb Vasc Biol 22: 1649-54

17. Shimano H, Yamada N, Ishibashi S, Mokuno H, Mori N, Gotoda T, Harada K, Akanuma Y, Murase T, Yazaki Y, Fumimaro Takaku. (1991) Oxidation-labile subfraction of human plasma low density lipoprotein isolated by ion-exchange chromatography. J Lipid Res 32: 763-73

18. Benitez S, Ordonez-Llanos J, Franco M, Marin C, Paz E, Lopez-Miranda J, Otal C, Perez-Jimenez F, Sanchez-Quesada JL. (2004) Effect of simvastatin in familial hypercholesterolemia on the affinity of electronegative low-density lipoprotein subfractions to the low-density lipoprotein receptor. Am J Cardiol 93: 414-20 
19. Zhang B, Matsunaga A, Rainwater DL, Miura S, Noda K, Nishikawa H, Uehara Y, Shirai K, Ogawa M, Saku K. (2009) Effects of rosuvastatin on electronegative LDL as characterized by capillary isotachophoresis: the ROSARY Study. J Lipid Res 50: $1832-41$

20. Vedie B, Jeunemaitre X, Megnien JL, Myara I, Trebeden H, Simon A, Moatti N. (1998) Charge heterogeneity of LDL in asymptomatic hypercholesterolemic men is related to lipid parameters and variations in the ApoB and CIII genes. Arterioscler Thromb Vasc Biol 18: 1780-9

21. Bittolo-Bon G, Cazzolato G, Avogaro P. (1994) Probucol protects low-density lipoproteins from in vitro and in vivo oxidation. Pharmacol Res 29: 337-44

22. Sanchez-Quesada JL, Benitez S, Otal C, Franco M, Blanco-Vaca F, Ordonez-Llanos J. (2002) Density distribution of electronegative LDL in normolipemic and hyperlipemic subjects. J Lipid Res 43: 699-705

23. Sanchez-Quesada JL, Perez A, Caixas A, Rigla M, Payes A, Benitez S, Ordonez-Llanos J. (2001) Effect of glycemic optimization on electronegative low-density lipoprotein in diabetes: relation to nonenzymatic glycosylation and oxidative modification. J Clin Endocrinol Metab 86: 3243-9 
24. Moro E, Alessandrini P, Zambon C, Pianetti S, Pais M, Cazzolato G, Bon GB. (1999) Is glycation of low density lipoproteins in patients with Type 2 diabetes mellitus a LDL pre-oxidative condition? Diabet Med 16: 663-9

25. Moro E, Zambon C, Pianetti S, Cazzolato G, Pais M, Bittolo Bon G. (1998) Electronegative low density lipoprotein subform (LDL-) is increased in type 2 (non-insulin-dependent) microalbuminuric diabetic patients and is closely associated with LDL susceptibility to oxidation. Acta Diabetol 35: 161-4

26. Sanchez-Quesada JL, Perez A, Caixas A, Ordonmez-Llanos J, Carreras G, Payes A, Gonzalez-Sastre F, de Leiva A. (1996) Electronegative low density lipoprotein subform is increased in patients with short-duration IDDM and is closely related to glycaemic control. Diabetologia 39: 1469-76

27. Ziouzenkova O, Asatryan L, Akmal M, Tetta C, Wratten ML, Loseto-Wich G, Jurgens G, Heinecke J, Sevanian A. (1999) Oxidative cross-linking of ApoB100 and hemoglobin results in low density lipoprotein modification in blood. Relevance to atherogenesis caused by hemodialysis. J Biol Chem 274: 18916-24

28. De Castellarnau C, Sanchez-Quesada JL, Benitez S, Rosa R, Caveda L, Vila L, Ordonez-Llanos J. (2000) Electronegative LDL from normolipemic subjects 
induces IL-8 and monocyte chemotactic protein secretion by human endothelial cells. Arterioscler Thromb Vasc Biol 20: 2281-7

29. Zhang B, Kaneshi T, Ohta T, Saku K. (2005) Relation between insulin resistance and fast-migrating LDL subfraction as characterized by capillary isotachophoresis. $\mathbf{J}$ Lipid Res 46: 2265-77

30. Schmitz G, Mollers C, Richter V. (1997) Analytical capillary isotachophoresis of human serum lipoproteins. Electrophoresis 18: 1807-13

31. Kitano S, Yoshida Y, Kawano K, Hibi N, Niki E. (2007) Oxidative status of human low density lipoprotein isolated by anion-exchange high-performance liquid chromatography--assessment by total hydroxyoctadecadienoic acid, 7-hydroxycholesterol, and 8-iso-prostaglandin F(2alpha). Anal Chim Acta 585: 86-93

32. Yamaguchi Y, Kagota S, Kunitomo M, Haginaka J. (1998) Evidence of modified lipoprotein in the plasma of Watanabe heritable hyperlipidemic rabbits by anion-exchange high-performance liquid chromatographic assay. Atherosclerosis 139: $323-31$

33. Bittolo-Bon G, Cazzolato G. (1999) Analytical capillary isotachophoresis of total 
plasma lipoproteins: a new tool to identify atherogenic low density lipoproteins. J Lipid Res 40: 170-7

34. de Queiroz Mello AP, da Silva IT, Oliveira AS, Nunes VS, Abdalla DS, Gidlund M, Damasceno NR. (2010) Electronegative low-density lipoprotein is associated with dense low-density lipoprotein in subjects with different levels of cardiovascular risk. Lipids 45: 619-25

35. Noda K, Zhang B, Uehara Y, Miura S, Matsunaga A, Saku K. (2005) Potent capillary isotachophoresis (cITP) for analyzing a marker of coronary heart disease risk and electronegative low-density lipoprotein (LDL) in small dense LDL fraction. Circ J 69: 1568-70

36. Lu J, Yang JH, Burns AR, Chen HH, Tang D, Walterscheid JP, Suzuki S, Yang CY, Sawamura T, Chen CH. (2009) Mediation of electronegative low-density lipoprotein signaling by LOX-1: a possible mechanism of endothelial apoptosis. Circ Res 104: 619-27

37. Kato T, Inoue T, Yamagishi S, Morooka T, Okimoto T, Node K. (2006) Low-density lipoprotein subfractions and the prevalence of silent lacunar infarction in subjects with essential hypertension. Hypertens Res 29: 303-7 
38. Yamaguchi Y, Matsuno S, Kagota S, Haginaka J, Kunitomo M. (2004) Peroxynitrite-mediated oxidative modification of low-density lipoprotein by aqueous extracts of cigarette smoke and the preventive effect of fluvastatin. Atherosclerosis 172: 259-65

39. Yamaguchi Y, Matsuno S, Kagota S, Haginaka J, Kunitomo M. (2001) Oxidants in cigarette smoke extract modify low-density lipoprotein in the plasma and facilitate atherogenesis in the aorta of Watanabe heritable hyperlipidemic rabbits. Atherosclerosis 156: 109-17

40. Yamaguchi Y, Kagota S, Haginaka J, Kunitomo M. (2000) Evidence of modified LDL in the plasma of hypercholesterolemic WHHL rabbits injected with aqueous extracts of cigarette smoke. Environ Toxicol Pharmacol 8: 255-60

41. Inoue N, Kawashima S, Hirata KI, Rikitake Y, Takeshita S, Yamochi W, Akita H, Yokoyama M. (1998) Stretch force on vascular smooth muscle cells enhances oxidation of LDL via superoxide production. Am J Physiol 274: H1928-32

42. Hishikawa K, Luscher TF. (1997) Pulsatile stretch stimulates superoxide production in human aortic endothelial cells. Circulation 96: 3610-6

43. Griendling KK, Sorescu D, Ushio-Fukai M. (2000) NAD(P)H oxidase: role in 
cardiovascular biology and disease. Circ Res 86: 494-501

44. Nakazono K, Watanabe N, Matsuno K, Sasaki J, Sato T, Inoue M. (1991) Does superoxide underlie the pathogenesis of hypertension? Proc Natl Acad Sci U S A 88: $10045-8$

45. Torres JL, Ridker PM. (2003) Clinical use of high sensitivity C-reactive protein for the prediction of adverse cardiovascular events. Curr Opin Cardiol 18: 471-8

46. Ridker PM. (2001) High-sensitivity C-reactive protein: potential adjunct for global risk assessment in the primary prevention of cardiovascular disease. Circulation 103: $1813-8$

47. Shoji T, Hatsuda S, Tsuchikura S, Shinohara K, Kimoto E, Koyama H, Emoto M, Nishizawa Y. (2009) Small dense low-density lipoprotein cholesterol concentration and carotid atherosclerosis. Atherosclerosis 202: 582-8 
Figure legends

(a)

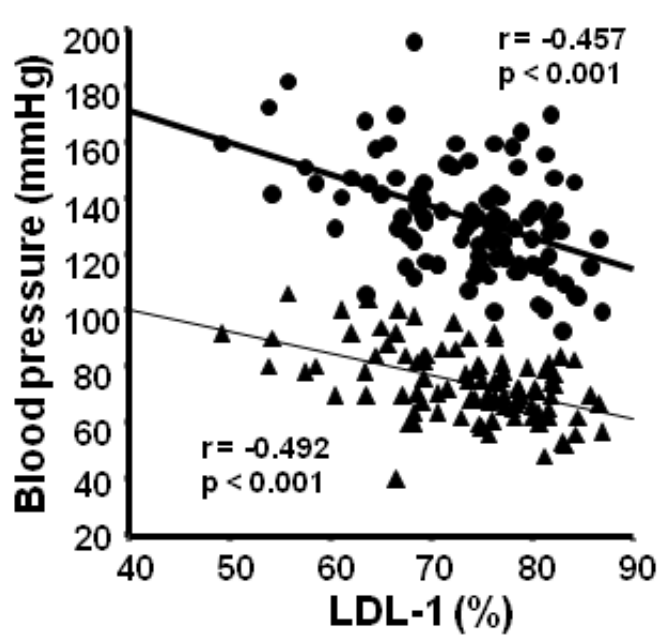

(b)

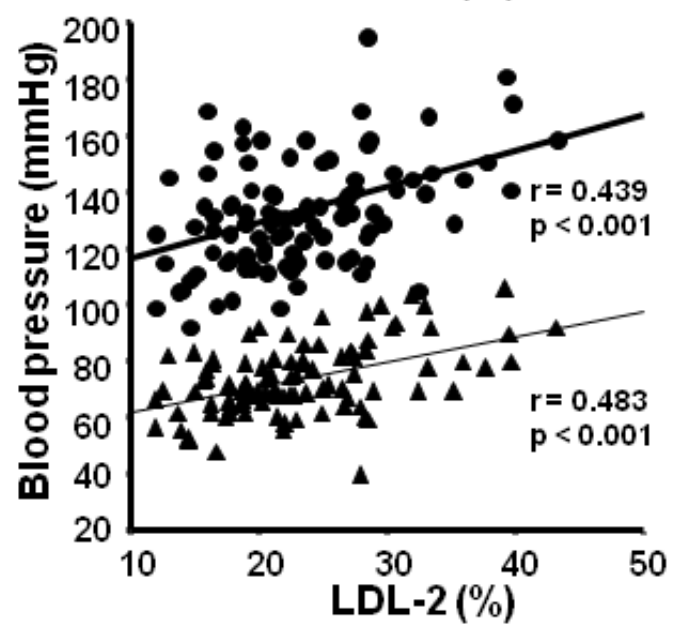

(c)

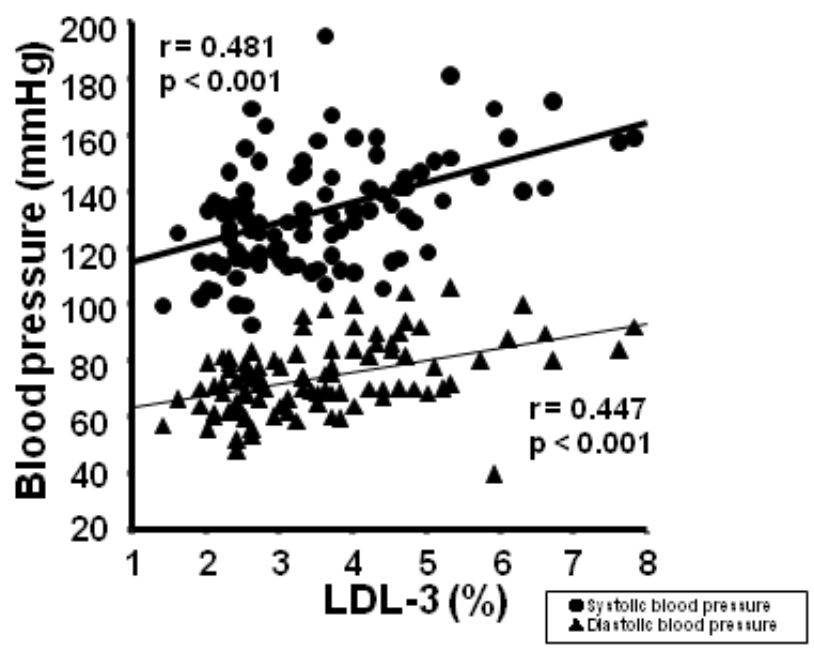

Figure 1. Correlations between

blood pressure and LDL

subfractions. Closed circles and

triangle indicate systolic and

diastolic blood pressure,

respectively. a, LDL-1; b, LDL-2;

c, LDL-3. 
(a)

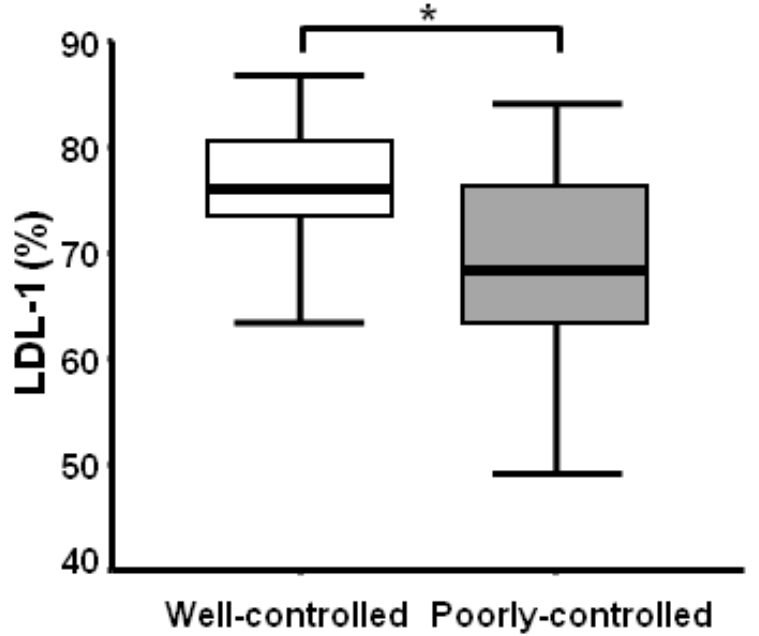

(b)

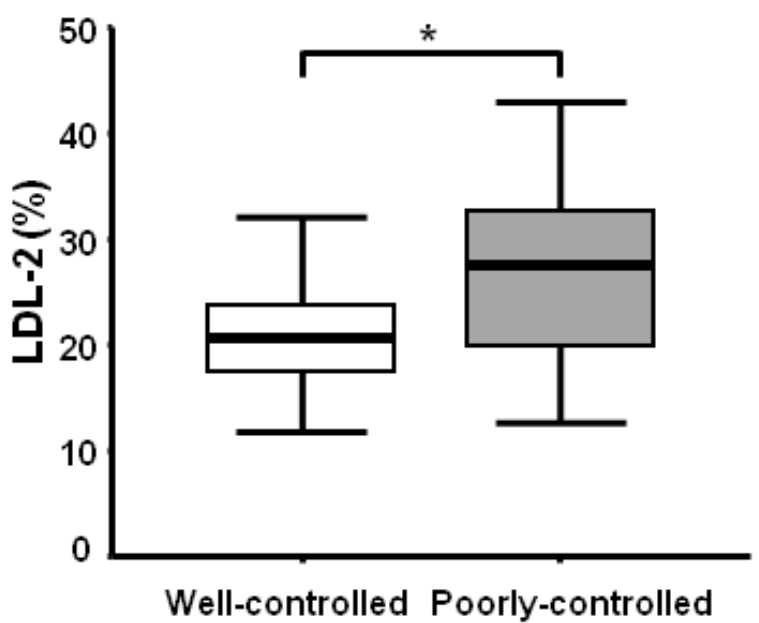

(c)

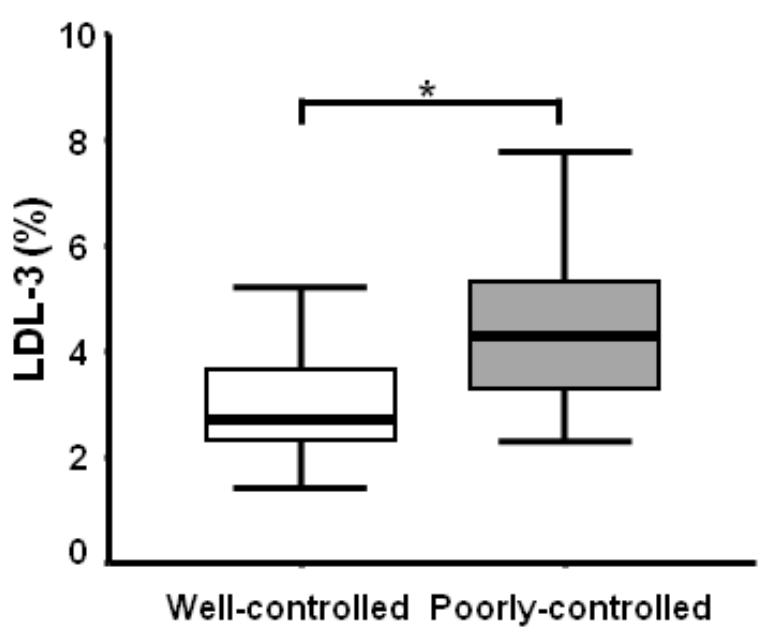

Figure 2. Levels of LDL

subfractions in individuals with

poorly and well-controlled

hypertension. Box plots indicate levels of LDL-1 (a), LDL-2 (b), and LDL-3 (c). Center horizontal lines indicate median values; upper and lower edges of outer boxes, $25^{\text {th }}$ and $75^{\text {th }}$ percentiles; lower and upper bars, $10^{\text {th }}$ and $90^{\text {th }}$ percentiles. ${ }^{*} \mathrm{p}<$ 0.01 . 


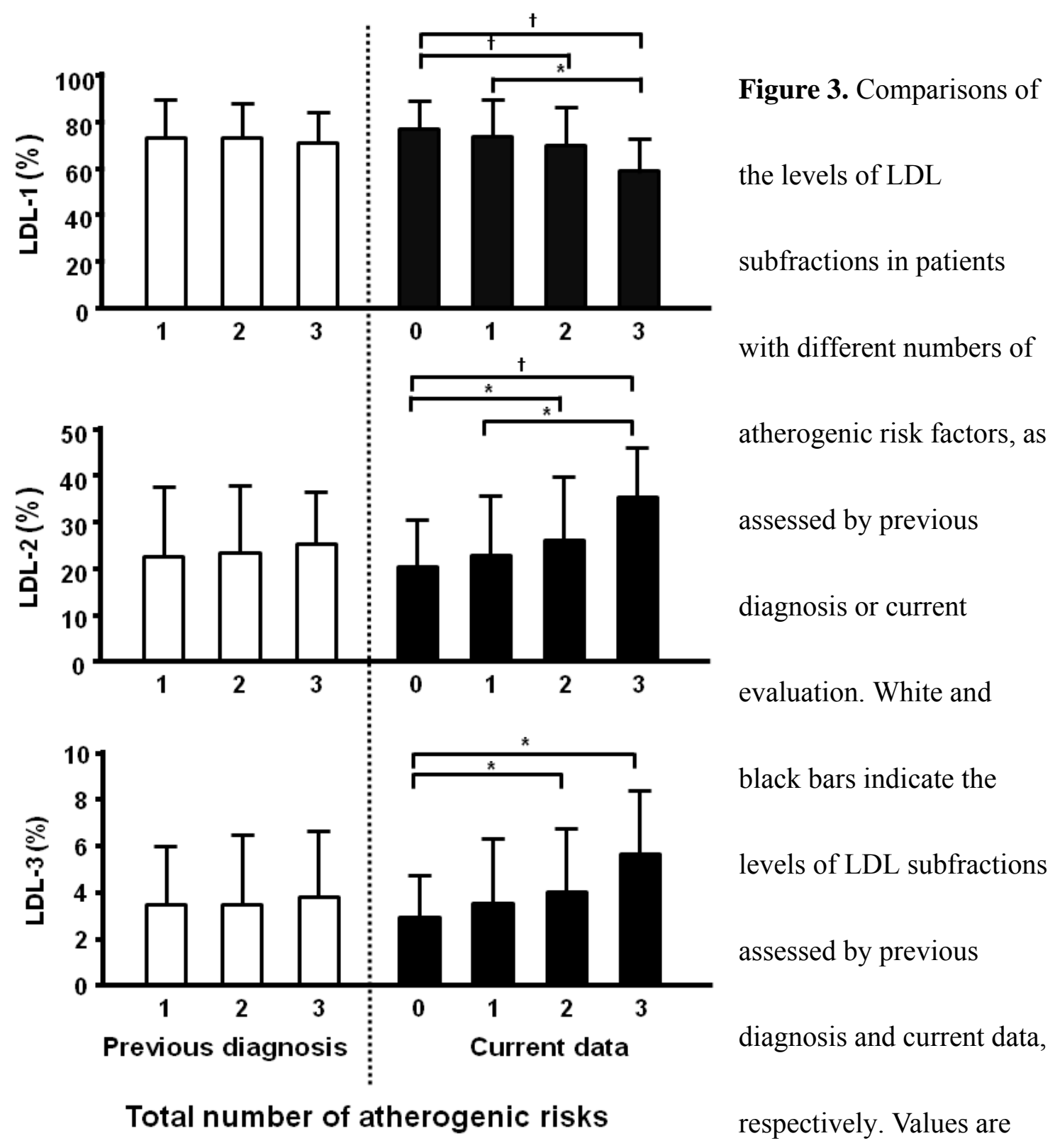

$$
\begin{aligned}
& \text { presented as means } \pm \text { SD. }{ }^{*} p \\
& <0.01,{ }^{\dagger} \mathrm{p}<0.05
\end{aligned}
$$


Table 1. Characteristics of patients

\begin{tabular}{|c|c|}
\hline Parameters & Mean \pm SD \\
\hline Age (years) & $67.0 \pm 10.7$ \\
\hline Gender (male : female) & $54: 44$ \\
\hline Body mass index $\left(\mathrm{kg} / \mathrm{m}^{2}\right)$ & $24.5 \pm 4.4$ \\
\hline Diabetes mellitus (\%) & 34.7 \\
\hline Dyslipidemia (\%) & 48.0 \\
\hline Smoking $(\%)$ & 43.9 \\
\hline Systolic blood pressure $(\mathrm{mmHg})$ & $133.0 \pm 19.7$ \\
\hline Diastolic blood pressure $(\mathrm{mmHg})$ & $74.1 \pm 12.5$ \\
\hline LDL-cholesterol (mg/dl) & $108.5 \pm 26.3$ \\
\hline Triglyceride (mg/dl) & $116.4 \pm 50.8$ \\
\hline HDL -cholesterol (mg/dl) & $49.9 \pm 11.9$ \\
\hline Fasting blood glucose $(\mathrm{mg} / \mathrm{dl})$ & $102.5 \pm 20.7$ \\
\hline Hemoglobin A1c (\%) & $5.75 \pm 0.61$ \\
\hline high-sensitive CRP (mg/L) & $3.69 \pm 8.23$ \\
\hline Anti-hypertensive medications use $(\%)$ & 96.9 \\
\hline Calcium channel antagonists (\%) & 55.1 \\
\hline ACE-I / ARB (\%) & 65.3 \\
\hline$\alpha$ receptor blocker $(\%)$ & 11.2 \\
\hline$\beta$ receptor blocker $(\%)$ & 28.6 \\
\hline Diuretics $(\%)$ & 20.4 \\
\hline Statin use $(\%)$ & 45.9 \\
\hline
\end{tabular}

LDL, low-density lipoprotein; HDL, high-density lipoprotein; CRP, C-reactive protein; ACE-I, Angiotensin-converting enzyme inhibitors; ARB, Angiotensin receptor blockers. 
Table 2. Characteristics of well- and poorly controlled hypertensive patients

\begin{tabular}{|c|c|c|}
\hline Parameters & $\begin{array}{l}\text { Well-controlled } \\
\qquad(\mathrm{n}=64)\end{array}$ & $\begin{array}{l}\text { Poorly controlled } \\
\qquad(\mathrm{n}=34)\end{array}$ \\
\hline Age (years) & $66.8 \pm 10.7$ & $67.3 \pm 10.7$ \\
\hline Gender (male : female) & $39: 25$ & $15: 19$ \\
\hline Body mass index $\left(\mathrm{kg} / \mathrm{m}^{2}\right)$ & $23.8 \pm 4.2$ & $25.9 \pm 4.4^{\dagger}$ \\
\hline Diabetes mellitus (\%) & 39.1 & 26.5 \\
\hline Dyslipidemia (\%) & 50.0 & 44.1 \\
\hline Smoking $(\%)$ & 54.7 & $23.5^{*}$ \\
\hline Systolic blood pressure (mmHg) & $121.7 \pm 11.2$ & $154.3 \pm 13.4^{*}$ \\
\hline Diastolic blood pressure $(\mathrm{mmHg})$ & $69.0 \pm 8.7$ & $83.6 \pm 13.1^{*}$ \\
\hline LDL-cholesterol (mg/dl) & $105.3 \pm 30.6$ & $117.5 \pm 23.6^{\dagger}$ \\
\hline Triglyceride (mg/dl) & $114.7 \pm 50.4$ & $119.7 \pm 52.2$ \\
\hline HDL -cholesterol (mg/dl) & $48.8 \pm 12.2$ & $51.9 \pm 11.1$ \\
\hline Fasting blood glucose (mg/dl) & $103.3 \pm 22.2$ & $101.1 \pm 17.9$ \\
\hline Hemoglobin A1c (\%) & $5.75 \pm 0.64$ & $5.72 \pm 0.57$ \\
\hline high-sensitive CRP (mg/L) & $4.74 \pm 9.88$ & $1.72 \pm 2.59^{\dagger}$ \\
\hline $\begin{array}{l}\text { Anti-hypertensive medications use } \\
(\%)\end{array}$ & 100.0 & 91.2 \\
\hline Calcium channel antagonists $(\%)$ & 53.1 & 58.8 \\
\hline ACE-I/ ARB (\%) & 73.4 & $50.0^{\dagger}$ \\
\hline$\alpha$ receptor blocker $(\%)$ & 7.8 & 17.7 \\
\hline$\beta$ receptor blocker $(\%)$ & 32.8 & 20.6 \\
\hline Diuretics $(\%)$ & 26.6 & $8.8^{\dagger}$ \\
\hline Statin use $(\%)$ & 53.1 & $32.4^{\dagger}$ \\
\hline 8-isoprostane (pg/ml) & $12.9 \pm 3.1$ & $14.8 \pm 5.1^{\dagger}$ \\
\hline Uric acid (mg/dl) & $5.85 \pm 1.37$ & $5.94 \pm 1.52$ \\
\hline
\end{tabular}

LDL, low-density lipoprotein; HDL, high-density lipoprotein; CRP, C-reactive protein; ACE-I, Angiotensin-converting enzyme inhibitors; ARB, Angiotensin receptor blockers. ${ }^{*} \mathrm{p}<0.01,{ }^{\dagger} \mathrm{p}<0.05$ 
Table 3. Correlations between LDL subfractions and atherogenic risk factors

\begin{tabular}{|c|c|c|c|c|c|c|}
\hline \multirow{2}{*}{ parameters } & \multicolumn{2}{|c|}{ LDL-1 } & \multicolumn{2}{c|}{ LDL-2 } & \multicolumn{2}{c|}{ LDL-3 } \\
\cline { 2 - 7 } & $\mathrm{r}$ & $\mathrm{P}$ value & $\mathrm{r}$ & $\mathrm{P}$ value & $\mathrm{r}$ & $\mathrm{P}$ value \\
\hline Body mass index & -0.384 & $\mathrm{p}<0.001$ & 0.396 & $\mathrm{p}<0.001$ & 0.267 & $\mathrm{p}=0.012$ \\
\hline Non-HDL-C & -0.403 & $\mathrm{p}<0.001$ & 0.398 & $\mathrm{p}<0.001$ & 0.357 & $\mathrm{p}<0.001$ \\
\hline Fasting blood glucose & -0.187 & $\mathrm{p}=0.067$ & 0.165 & $\mathrm{p}=0.106$ & 0.274 & $\mathrm{p}=0.007$ \\
\hline HbA1c & -0.143 & $\mathrm{p}=0.207$ & 0.120 & $\mathrm{p}=0.288$ & 0.244 & $\mathrm{p}=0.029$ \\
\hline Uric acid & 0.125 & $\mathrm{p}=0.237$ & -0.125 & $\mathrm{p}=0.235$ & -0.091 & $\mathrm{p}=0.391$ \\
\hline high sensitive CRP & 0.088 & $\mathrm{p}=0.390$ & -0.097 & $\mathrm{p}=0.343$ & -0.035 & $\mathrm{p}=0.733$ \\
\hline 8-isoprostane & -0.415 & $\mathrm{p}<0.001$ & 0.412 & $\mathrm{p}<0.001$ & 0.337 & $\mathrm{p}=0.001$ \\
\hline
\end{tabular}

